\title{
Research on Evaluation of Power Enterprise Safety Management Capability Based on Gray AHP
}

\author{
Yi-Ming Zhao \\ Department of Electrical Engineering, North China Electric Power University, Baoding, China
}

2948439919@qq.com

Keywords: Power enterprise; Safety management capability; Evaluation index system; Gray analytic hierarchy process

\begin{abstract}
The feature of electric enterprise safety management capability evaluation system was analyzed according to the new study of the safety management theory and the system theory. An evaluation index system of electric enterprise safety management capability was built up based on the study of the hierarchy process of electric enterprise safety management capability and their relation. A corresponding evaluation method was given by using gray analytic hierarchy process.
\end{abstract}

\section{Introduction}

With the construction of power grid speeding up, the power grid restructuring and operating mode change more and more frequent. In addition, the influence of external damage and bad weather increased a lot, and the problem of power security and stability becomes more and more prominent [1]. Given the lack of security situation of power enterprise management situation and the current security management analysis tools, it is urgent to take safety analysis methods and tools to systematically and comprehensively analyze the specific situation of power enterprises. In response to the proposed demand, this paper proposed an Power enterprise security management evaluation system based on gray analytic hierarchy process [2]. This system contains 3 analysis units: provincial, municipal and county-level. The quantitative description and dynamic measurement traceability system is established for the actual level of safety management capacity. The modern enterprise safety management theory and system engineering theory and methods are applied to analyze the safety management level of the power enterprises, which can not only comprehensively reflect the integrated enterprise security management status, but also dynamically reflect the development potential of power enterprises, transfer the security management from passive to active, and make more good service in the electricity enterprise security management [3].

\section{The Establishment Of The Evaluation Index System}

The analysis of power enterprise security management capabilities should examine the following two aspects: First is the content knowledge and skills of security system configuration factors, namely, staff, equipment, systems, power grids and the environment these five elements of knowledge and skills of the case; the second is security system performance improvement, namely the security elements of the system should have the ability to improve dynamically.

Therefore, the power enterprise security management capability can be divided into the following five aspects:

(1) Ability to protect employee safety operations; (2) Ability to monitor the use of safety equipment; (3) Ability to improve the safety regulatory level; (4) Ability to optimize the power supply safety; (5) Ability to improve safety in production environments.

These five aspects ability (Feature layer) can be decomposed into different component (Discriminating layer) according to the specific circumstances. Each component can be decomposed into a set of the most basic element (Index layers). Structural relationship at all levels is shown in Table 1.

These five aspects should be considered in the power enterprise security management capacity evaluation. Through the index system related security capabilities statistical analysis, effectively 
identify all aspects of the ability, and analyze the growth approach of the enterprise security management capabilities. Then, the comprehensive performance improvement of the security system can be achieved.

Table 1. Power enterprise security management capability evaluation index system

\begin{tabular}{|c|c|c|}
\hline Feature layer & Discriminating layer & Index layers \\
\hline \multirow{11}{*}{$\begin{array}{l}\text { Ability to protect } \\
\text { employee safety } \\
\text { operations } B_{1}\end{array}$} & \multirow{4}{*}{$\begin{array}{l}\text { Safety education } \\
\text { component } \mathrm{C}_{1}\end{array}$} & $\begin{array}{c}\text { Security level of protection of educational } \\
\text { resources } D_{1}\end{array}$ \\
\hline & & $\begin{array}{l}\text { Security level of implementation of the education } \\
\text { system } D_{2}\end{array}$ \\
\hline & & Safety quality assessment qualified level $\mathrm{D}_{3}$ \\
\hline & & Personnel accidents level $\mathrm{D}_{4}$ \\
\hline & \multirow{4}{*}{$\begin{array}{l}\text { Field control } \\
\text { component } \mathrm{C}_{2}\end{array}$} & "Two votes" executive level $\mathrm{D}_{5}$ \\
\hline & & Standard operating level $\mathrm{D}_{6}$ \\
\hline & & Security auditing organization level $\mathrm{D}_{7}$ \\
\hline & & Safe and civilized construction level $\mathrm{D}_{8}$ \\
\hline & \multirow{3}{*}{$\begin{array}{l}\text { Equipment support } \\
\text { component } C_{3}\end{array}$} & Safety equipment protection level $\mathrm{D}_{9}$ \\
\hline & & Horizontal construction equipment operations $\mathrm{D}_{10}$ \\
\hline & & Anti-error device management level $\mathrm{D}_{11}$ \\
\hline \multirow{7}{*}{$\begin{array}{l}\text { Ability to monitor } \\
\text { the use of safety } \\
\text { equipment } \mathrm{B}_{2}\end{array}$} & \multirow{3}{*}{$\begin{array}{l}\text { Staff support } \\
\text { component } \mathrm{C}_{4}\end{array}$} & Production staffing level $\mathrm{D}_{12}$ \\
\hline & & Production staff training level $\mathrm{D}_{13}$ \\
\hline & & Equipment accident level $\mathrm{D}_{14}$ \\
\hline & \multirow{2}{*}{$\begin{array}{l}\text { Device Management } \\
\text { component } \mathrm{C}_{5}\end{array}$} & Device file system level $\mathrm{D}_{15}$ \\
\hline & & Executive management system level $\mathrm{D}_{16}$ \\
\hline & \multirow{2}{*}{$\begin{array}{l}\text { Technical support } \\
\text { component } \mathrm{C}_{6}\end{array}$} & Technology safeguards level $\mathrm{D}_{17}$ \\
\hline & & Repair and test equipment level $\mathrm{D}_{18}$ \\
\hline \multirow{4}{*}{$\begin{array}{l}\text { Ability to improve } \\
\text { the safety regulatory } \\
\text { level } \mathrm{B}_{3}\end{array}$} & \multirow{2}{*}{$\begin{array}{c}\text { Organizational } \\
\text { security component } \\
\mathrm{C}_{7} \\
\end{array}$} & Security responsibilities system level $\mathrm{D}_{19}$ \\
\hline & & Safety supervision organization security level $\mathrm{D}_{20}$ \\
\hline & $\begin{array}{l}\text { System security } \\
\text { component } C_{8}\end{array}$ & Safety system protection level $\mathrm{D}_{21}$ \\
\hline & $\begin{array}{c}\text { Implementation force } \\
\text { component } C_{9}\end{array}$ & Security system executive level $D_{22}$ \\
\hline \multirow{7}{*}{$\begin{array}{l}\text { Ability to optimize } \\
\text { the power supply } \\
\text { safety } B_{4}\end{array}$} & \multirow{3}{*}{$\begin{array}{l}\text { Optimization } \\
\text { component } \mathrm{C}_{10}\end{array}$} & Urban grid structure optimization level $\mathrm{D}_{23}$ \\
\hline & & Security electricity supply level $\mathrm{D}_{24}$ \\
\hline & & Power quality index level $\mathrm{D}_{25}$ \\
\hline & \multirow{2}{*}{$\begin{array}{l}\text { Communication and } \\
\text { coordination } \\
\text { component } \mathrm{C}_{11}\end{array}$} & $\begin{array}{c}\text { Communication and coordination grid scheduling } \\
\text { level } \mathrm{D}_{26}\end{array}$ \\
\hline & & $\begin{array}{l}\text { Power facilities protection and coordination level } \\
\qquad D_{27}\end{array}$ \\
\hline & \multirow{2}{*}{$\begin{array}{c}\text { Emergency repair } \\
\text { component } \mathrm{C}_{12}\end{array}$} & Materials and equipment protection level $\mathrm{D}_{28}$ \\
\hline & & Repair tissue security level $\mathrm{D}_{29}$ \\
\hline \multirow{3}{*}{$\begin{array}{l}\text { Ability to improve } \\
\text { safety in production } \\
\text { environments } B_{5}\end{array}$} & $\begin{array}{l}\text { Cultural support } \\
\text { component } \mathrm{C}_{13}\end{array}$ & Safety culture construction level $\mathrm{D}_{30}$ \\
\hline & \multirow{2}{*}{$\begin{array}{l}\text { Facilities component } \\
\mathrm{C}_{14}\end{array}$} & Standardization construction level $\mathrm{D}_{31}$ \\
\hline & & Qualified safety level $D_{32}$ \\
\hline
\end{tabular}

\section{Evaluation Method}

As the power enterprise security management is a complex integrated qualitative and quantitative indicators, this paper proposes the use of systems engineering AHP and gray combination of theoretical methods to study the power enterprise security management capabilities hierarchical 
structure and theirs relationships.

Combining with the actual situation of power companies, the security management capacity assessment should consider the total level layer, feature layer, discriminating layer, and index layer. In AHP, the value of different levels of decision-making power is calculated by using the gray theory. Power enterprise security management capabilities specific assessment steps are as follows:

(1) Determine the hierarchical structure of the enterprise security management capabilities Index System. To determine the safety management capacity indicators would need to follow the scientific, practical, feasible, rationality and the principle of comparability, Table 1 shows the level of power enterprise security management capability evaluation index system.

(2) Calculate an evaluation index system for the combination of the underlying elements of target weight. In index system, the main index layer is $A=\left(B_{1}, B_{2}, B_{3}, B_{4}, B_{5}\right)$, and its weight is $a=\left(b_{1}, b_{2}, b_{3}, b_{4}, b_{5}\right)$. In $\mathrm{B}$ level index layer, $B_{1}=\left(C_{1}, C_{2}, C_{3}\right)$, and its weight is $b_{1}=\left(c_{1}, c_{2}, c_{3}\right)$; $B_{2}=\left(C_{4}, C_{5}, C_{6}\right)$, and its weight is $b_{2}=\left(c_{4}, C_{5}, C_{6}\right) ; B_{3}=\left(C_{7}, C_{8}, C_{9}\right)$, and its weight is $b_{3}=\left(c_{7}, c_{8}, c_{9}\right) ; B_{4}=\left(C_{10}, C_{11}, C_{12}\right)$, and its weight is $b_{4}=\left(c_{10}, c_{11}, c_{12}\right) ; B_{5}=\left(C_{13}, C_{14}\right)$, and its weight is $b_{5}=\left(c_{13}, c_{14}\right)$. In $\mathrm{C}$ level index layer, $C_{1}=\left(D_{1}, D_{2}, D_{3}, D_{4}\right)$, and its weight is $c_{1}=\left(d_{1}, d_{2}, d_{3}, d_{4}\right) ; C_{2}=\left(D_{5}, D_{6}, D_{7}, D_{8}\right)$, and its weight is $c_{2}=\left(d_{5}, d_{6}, d_{7}, d_{8}\right)$. And so on, all of the parameter values can be obtained. Then, calculate the feature vectors of $\mathrm{A}, \mathrm{B}$ and $\mathrm{C}$. The feature vector component is the corresponding element of the relative weight of the upper element of weight.

The combination weight from underlying elements to target $W=\left(w_{1}, w_{2}, \mathrm{~L}, w_{32}\right)$ is obtained through multiplying the weight of each layers, such as $w_{1}=b_{1} \cdot c_{1} \cdot d_{1}, \quad w_{2}=b_{1} \cdot c_{1} \cdot d_{2}$, $w_{32}=b_{5} \cdot c_{14} \cdot d_{32}$.

(3) Calculate the evaluation index value matrix $D_{J I}^{(A)}(A=1,2, \mathrm{~L}, 32)$.

$$
D_{J I}^{(A)}=\left[\begin{array}{cccc}
d_{11}^{(A)} & d_{12}^{(A)} & \mathrm{L} & d_{1 i}^{(A)} \\
d_{21}^{(A)} & d_{22}^{(A)} & \mathrm{L} & d_{2 i}^{(A)} \\
\mathrm{M} & \mathrm{M} & \mathrm{O} & \mathrm{M} \\
d_{j 1}^{(A)} & d_{j 1}^{(A)} & \mathrm{L} & d_{j i}^{(A)}
\end{array}\right]
$$

Where $D_{J I}^{(A)}$ is the A-th evaluation indicator value matrix of J-th power enterprise assessed by I-th evaluator.

(4) Determine the evaluation gray class. Set $K=4$, namely there are four gray classes which includes "Excellent", "Good", "Medium" and "Poor". Their corresponding gray number and whitening weight function are as follows:

The first gray class, "Excellent", $(K=1)$, set gray number as $\otimes 1 \in[9, \infty]$, whitening weight function as $f_{1}$ :

$$
f_{1}\left(d_{j i}\right)= \begin{cases}d_{j i} / 9, & d_{j i} \in[0,9] \\ 1, & d_{j i} \in[9, \infty) \\ 0, & d_{j i} \in(-\infty, 0]\end{cases}
$$

The second gray class, "Good", ( $K=2)$, set gray number as $\otimes 2 \in[0,7,14]$, whitening weight function as $f_{2}$ :

$$
f_{2}\left(d_{j i}\right)=\left\{\begin{array}{l}
d_{j i} / 7, \quad d_{j i} \in[0,7] \\
2-d_{j i} / 7, \quad d_{j i} \in[7,14] \\
0, \quad d_{j i} \notin[0,14]
\end{array}\right.
$$


The third gray class, "Medium", $(K=3)$, set gray number as $\otimes 3 \in[0,5,10]$, whitening weight function as $f_{3}$ :

$$
f_{3}\left(d_{j i}\right)=\left\{\begin{array}{l}
d_{j i} / 5, \quad d_{j i} \in[0,5] \\
2-d_{j i} / 5, \quad d_{j i} \in[5,10] \\
0, \quad d_{j i} \notin[0,10]
\end{array}\right.
$$

The fourth gray class, "Poor", $(K=4)$, set gray number as $\otimes 4 \in[0,1,4]$, whitening weight function as $f_{4}$ :

$$
f_{4}\left(d_{j i}\right)=\left\{\begin{array}{l}
1, \quad d_{j i} \in[0,1] \\
\left(4-d_{j i}\right) / 3, \quad d_{j i} \in[1,4] \\
0, \quad d_{j i} \notin[0,4]
\end{array}\right.
$$

(5) Calculate the gray evaluation coefficient. The K-th class gray evaluation coefficient of A-th index of the J-th power enterprise can be obtained from $D_{J I}^{(A)}$ and $f_{K}\left(d_{j i}\right)$, which is defined as $n_{J K}^{(A)}$ :

$$
n_{J K}^{(A)}=\sum_{I=1}^{i} f_{K}\left(d_{J K}^{(A)}\right)
$$

For the evaluation index A, commentary by power companies belonging to $\mathrm{J}$ total ash gray evaluate coefficients of each assessment category $n_{J}^{(A)}$, there are:

$$
n_{J}^{(A)}=\sum_{I=1}^{4} n_{J K}^{(A)}
$$

(6) Calculate the gray evaluation weight vector and weight matrix. The K-th gray class of J-th power enterprise of them can be obtained from $n_{J K}^{(A)}$ and $n_{J}^{(A)}$, and are defined as $r_{J K}^{(A)}$ and $r_{J}^{(A)}$ :

$$
\begin{aligned}
& r_{J K}^{(A)}=n_{J K}^{(A)} / n_{J}^{(A)} \\
& r_{J}^{(A)}=\left\{r_{J 1}^{(A)}, r_{J 2}^{(A)}, \mathrm{L}, r_{J K}^{(A)}\right\}
\end{aligned}
$$

Moreover, the gray evaluation weight matrix of evaluation index A from all power enterprises $R^{(A)}=\left\{r_{J K}^{(A)}\right\}$ can be calculated.

$$
R^{(A)}=\left[\begin{array}{cccc}
r_{11}^{(A)} & r_{12}^{(A)} & r_{13}^{(A)} & r_{14}^{(A)} \\
r_{21}^{(A)} & r_{22}^{(A)} & r_{23}^{(A)} & r_{24}^{(A)} \\
\mathrm{M} & \mathrm{M} & \mathrm{M} & \mathrm{M} \\
r_{j 1}^{(A)} & r_{j 2}^{(A)} & r_{j 3}^{(A)} & r_{j 4}^{(A)}
\end{array}\right]
$$

(7) Evaluate different evaluation index. From $R^{(A)}$, it can get $r_{J K}^{*(A)}=\max \left\{r_{J K}^{(A)}\right\}$. Then, the index evaluation weight vector can be obtained:

$$
r^{*(A)}=\left\{r_{1}^{*(A)}, r_{2}^{*(A)}, \mathrm{L}, r_{j}^{*(A)}\right\}
$$

According to the results of $r^{*(A)}$, the power enterprise gray class of different indicators can be obtained.

(8) Comprehensively evaluate the power enterprise security management capabilities. Arrange $(A=1,2, \mathrm{~L}, 32)$ into the matrix $r^{*}$ which includes 32 rows and $\mathrm{J}$ arrays. $r^{*}$ is defined as the comprehensive evaluation weight matrix. Compute $r_{J}=W \times r^{*}$, we can obtain the comprehensive evaluation value $r_{J}$. Depending on the size of the assessed value of the merits of the order can be discharged by the power companies comprehensive assessment of all indicators after the enterprise security management capabilities. 
Through the implementation of power safety management evaluation, the following goals can be achieved: (1) Establish the enterprise security management evaluation index system database and achieve computer management. (2) Establish enterprise security management capacity factor index analysis system and achieve the targets longitudinal, transverse and comparative dynamic analysis. (3) Provide security control dynamics analysis system. Through varying the intensity of security control, time and direction, analyze developments in enterprise security management capabilities.

\section{Conclusions}

The Analysis and evaluation of power corporate security management is using modern theory and methods to comprehensively analyze the factors affecting the safety of power enterprises. Use theoretical methods and safety system engineering theory and analyze the relationship between the factors of power between enterprise security systems, establish the electricity enterprise security management evaluation system. Establishing a scientific and objective electricity enterprise security management evaluation system is not only to provide decision-making reference for enterprises to develop scientific and reasonable security strategy, but also can improve the optimal allocation of the level of corporate security resource inputs and help enterprises integrate resources, improve enterprise security management level.

\section{References}

[1] Liu Chao, Luo Yun, Li Jiarong. Research on the Evaluation Index System for Employees' Safety Quality of Electric Power Enterprises Based on AHP. China Safety Science Journal, Volume 19, Issue 9 (2009), P. 132-138.

[2] Zhang Hong, Liu Dunyi. Evaluation Index Systems of Electric Enterprise Safety Management Capability. Journal of WUT (Information and management engineering), Volume 30, Issue 4 (2008), P. 662-664.

[3] Wang Wei, Chen Xiaoqiang. Human resources optimal allocation method based on fuzzy mathematics. China Management Informationization, Volume 11, Issue 6 (2008), P. 93-95. 